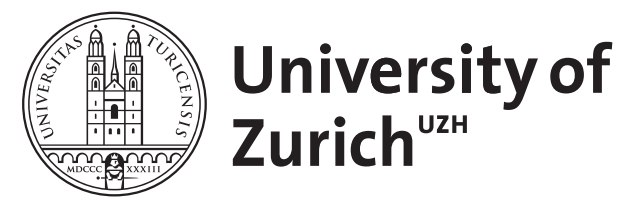

\title{
Der Koran und seine Rezeption
}

\author{
Würsch, Renate
}

\begin{abstract}
The focus of this paper lies on the Islamic approach to the Qurª̄n, the exegesis of the text, and the significance of Qurª̄nic revelation for Muslim societies ("Sitz im Leben") for centuries up to the present day, paying also some attention to the history of the European perception of the Qurª̄n, from which ultimately modern Western Qurª̄nic research emerged. As an introduction, the specific formal and thematic features of the Qur ${ }^{\circ} \bar{a} n$, Islam's Holy Scripture, are explained and the history of the Qur ${ }^{\circ} \bar{n} n i c$ text is summarized. The last topic is the historic, social, and literary contextualisation of the Qur ${ }^{\circ} \bar{a} n$ as well as its aesthetic dimension (e.g. the "audible" and the "visible" Qurª̄n as artistic manifestations). The discussion includes a review of recent scholarship, which has developed some pioneering new concepts about early Qur ${ }^{\circ} \bar{n}$ ic textual history and the (re)location of the Qur $^{\circ} \bar{a} n$ in its historical context in Late Antiquity.
\end{abstract}

DOI: https://doi.org/10.1524/mial.2013.0003

Posted at the Zurich Open Repository and Archive, University of Zurich

ZORA URL: https://doi.org/10.5167/uzh-91101

Journal Article

Published Version

Originally published at:

Würsch, Renate (2013). Der Koran und seine Rezeption. Das Mittelalter. Perspektiven mediävistischer Forschung, 18(1):27-45.

DOI: https://doi.org/10.1524/mial.2013.0003 


\title{
Der Koran und seine Rezeption
}

\author{
RENATE WÜRSCH
}

\begin{abstract}
The focus of this paper lies on the Islamic approach to the Qur'ān, the exegesis of the text, and the significance of Qur'ānic revelation for Muslim societies ("Sitz im Leben") for centuries up to the present day, paying also some attention to the history of the European perception of the Qur'ān, from which ultimately modern Western Qur'ānic research emerged. As an introduction, the specific formal and thematic features of the Qur'ān, Islam's Holy Scripture, are explained and the history of the Qur'ānic text is summarized. The last topic is the historic, social, and literary contextualisation of the Qur'ān as well as its aesthetic dimension (e.g. the "audible" and the "visible" Qur'ān as artistic manifestations). The discussion includes a review of recent scholarship, which has developed some pioneering new concepts about early Qur' $\bar{a}-$ nic textual history and the (re)location of the Qur'ān in its historical context in Late Antiquity.
\end{abstract}

Keywords: Islam; revelation; Late Antiquity; canonisation; textualisation

Der Koran ist ohne Zweifel einer der faszinierendsten und wirkungsmächtigsten Texte der Weltliteratur. Die islamische Geschichte, Kultur und Gesellschaft hat er wie kein anderes Werk geprägt. Für die Gläubigen ist er zunächst und in erster Linie vor allem die Schrift gewordene göttliche Offenbarung (wahy), also Wort Gottes, das der Prophet Mohammed durch Verbalinspiration empfangen hat. Als Text hat der Koran aber auch eine ästhetische Dimension, die seiner religiösen Bedeutung nicht nachsteht.

Im Folgenden sollen drei für den Koran und seine Rezeption wichtige Themenbereiche behandelt werden: (1) formale und inhaltliche Aspekte des Korans als Text; dabei werden einige Charakteristika des Korans erläutert, die seine Einzigartigkeit mitbedingen. (2) Aspekte der koranischen Textgeschichte und Rezeption. Der Schwerpunkt liegt dabei auf der innerislamischen Rezeption des Korans, dem Umgang mit ihm und seiner Bedeutung für islamisch geprägte Gesellschaften. Der Koran ist nicht nur der grundlegende Referenztext einer islamisch definierten Kultur, er hat unzählige literarische Texte - auch solche nicht primär religiösen Inhalts - inspiriert, und er hat ganze Wissenschaftszweige begründet, zunächst die Gattung des Kommentars, dann aber auch die Koranphilologie, die ihrerseits einen wichtigen Impuls für die Entwicklung einer autochthonen arabischen Literaturtheorie gegeben hat. Im Anschluss an die Darlegungen zur innerislamischen Rezeption des Korans soll auch die Geschichte seiner europäischen Rezeption gestreift werden, aus der sich letztlich die moderne westliche Koranforschung entwickelt hat. (3) Erörtert wird schließlich die historische, sozialgeschichtliche und literarische Kontextualisierung des Korans sowie seine ästhetische Dimension, an deren Beispiel sich die Übertragung einer heiligen Schrift in andere Vermittlungsformen zeigen lässt; denn der Koran wird nicht nur auf der Textebene als sprachlich-literarisches Kunstwerk verstanden, er ist als hörbarer und sichtbarer Koran auch auf andere Kontexte künstlerischer Repräsentation übertragen worden: Für den Bereich des Hörens ist die hochentwickelte Kunst der Koranrezitation zu nennen, für den visuellen Bereich insbesondere Buchmalerei und Architektur. Dabei sei auch Rekurs auf 
die aktuelle Forschung genommen, die in jüngster Zeit namentlich in Bezug auf die frühe Textgeschichte und Rezeption des Korans sowie seine Verortung im historischen Kontext neue Ansätze entwickelt und herausgearbeitet hat. ${ }^{1}$ Dabei ist besonders auf das Projekt „Corpus coranicum“ in Berlin zu verweisen, das eine kommentierte historisch-kritische Edition des Korantexts zum Ziel hat und das den als Text der Spätantike verstandenen Koran in eben diesem Umfeld zu relokalisieren sucht. Es baut dabei auf der These auf, dass der Koran als Text der Spätantike eine gemeinsame Wurzel mit dem ebenfalls auf der Spätantike fußenden christlich-jüdisch geprägten Europa hat und somit auch als ein Text zu verstehen ist, der „europäisch“ gelesen werden sollte.

\section{Formale und inhaltliche Aspekte des Korans}

Was beim Koran auf formaler Ebene zunächst auffällt, ist seine Gliederung in 114 Abschnitte (,Suren“, suwar, sg. süra), die ihrerseits in Verse (āyāt) eingeteilt sind. Der Begriff „Sure“ geht etymologisch auf das Syrische zurück und scheint für die früheste muslimische Glaubensgemeinschaft die Funktion eines gottesdienstlichen Lesungsabschnittes gehabt zu haben - wie er auch aus den monotheistischen Nachbarreligionen bekannt war. ${ }^{2}$ Verfasst ist der Text des Korans in rhythmisierter Prosa, wobei einzelne Sequenzen durch Reime gegliedert werden. Mit Ausnahme der 9. Sure (Sūrat at-tawba oder Sūrat al-barā'a) wird jede Sure des Korans durch die Formel bi-smi llāhi r-rạ̣māni r-raḥim, die sog. Basmala, eingeleitet. ${ }^{3}$ Alle Suren haben Namen, und sie werden in der islamischen Tradition mit ihren Namen, nicht nach ihrer Nummer bezeichnet. Die Namen bestehen meist aus einem dem Anfang der Sure entnommenen Schlüsselwort oder aus einem Begriff, der für die Thematik der betreffenden Sure besondere Bedeutung hat. Die erste Sure wird die „Eröffnende" (al-fātiḩa) genannt; sie ist ein Gebet, das für das religiöse Leben von prägender Bedeutung ist, so auch für das fünfmal am Tag zu verrichtende Ritualgebet:

1 bi-smi llāhi r-raḥmāni r-rahīm

2 al-ḥamdu li-llāhi rabbi l-'ālamīn

3 ar-rahmāni r-rahìm

4 māliki yawmi d-dīn

5 iyyāka na budu wa-iyyāka nasta ìn

6 ihdinā ș-ṣirāta l-mustaqīm

7 șirăta l-ladīna an 'amta 'alayhim

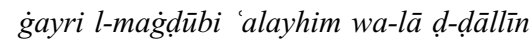

Im Namen Gottes des allbarmherzigen Erbarmers,

Gelobt sei Gott, der Herr der Welten,

Der Allbarmherzige, der Erbarmer,

Der König des Gerichtstags.

Dir dienen wir, dich rufen wir um Hilf' an.

Führ' uns den Weg den graden!

Den Weg derjenigen, über die du gnadest,

Deren auf die nicht wird gezürnt, und deren die nicht irrgehn. ${ }^{4}$

1 Vgl. Angelika Neuwirth, Der Koran als Text der Spätantike. Ein europäischer Zugang. Berlin 2010; nicht nur eine exemplarische Darstellung des derzeitigen Forschungsstandes, sondern auch der Geschichte der Koranforschung.

2 Dazu ebd., S. 278 mit spezifischen Erläuterungen zum syrischen Kontext.

3 William A. Graham, Basmala. In: Jane Dammen McAuliffe (Hg.), Encyclopaedia of the Qur'ān. Bd. 1 (2001), S. 207-212, hier S. 207. Die Basmala erscheint auch als Eröffnung von Salomos Brief an die Königin von Saba (27/30), insgesamt also 114 Mal im Koran.

4 Wenn nicht anders vermerkt, wird die Koran-Übersetzung von Friedrich Rückert zitiert: Der Koran in der Übersetzung von Friedrich Rückert. Hrsg. v. Hartmut Bobzin. 3. Aufl. Würzburg 2000. 
Die Gliederung der Sequenzen durch Reime ist deutlich zu erkennen, wobei diese Reime nicht so streng sind wie jene in der altarabischen Dichtung - so reimt $-\bar{l} n$ auf $-\bar{l} m$ und umgekehrt, und in Vers 3 wird ein Reimwort (rahim) wiederholt, während in der Dichtung die Wiederholung von Reimwörtern nur nach strikten Regeln gestattet ist. Die Verssequenzen sind mit Ausnahme von Vers 7 kurz, sie entsprechen einander in der Länge, Silbenzahl und Quantität der Silben aber nicht: So sind etwa die Verse 3 und 4 viel kürzer als die übrigen und Vers 7 beginnt mit einer kurzen Silbe, während am Anfang der übrigen Verse jeweils eine positionslange bzw. naturlange (Vers 4) Silbe steht. Die Verse weisen kein Metrum auf - es handelt sich also nicht um Poesie - sie zeichnen sich aber durch eine starke Rhythmisierung aus, was sie in enormem Maß einprägsam macht. Der lange Vers 7 hält die Spannung in der Schwebe und bereitet dadurch auf den Schluss der gesamten Texteinheit vor, der mit dem letzten Reimwort dällīn erreicht wird.

Obwohl ein von einem geschulten Rezitator ausgeführter Koranvortrag in mancher Hinsicht an Gesang erinnert, ist es wichtig, festzuhalten, dass es sich nach islamischem Verständnis keinesfalls um Gesang handelt; der Koranvortrag ist eine Rezitation, der Ausführende wird denn auch als „Leser“ oder „Rezitator“, nie als „Sänger“ bezeichnet. ${ }^{5}$

Während die Fātiha ein Gebet ist, das von den Gläubigen an Gott gerichtet wird, ist sonst im Koran als „Wort Gottes“ immer Gott der Redende. Der im Islam so grundlegende Glaubenssatz, dass Gott einer ist, wird in der Fātiha indirekt in Vers 2 ausgesprochen: Gott ist der „Herr der Welten“, seine Herrschaft und seine Macht sind allumfassend. Klar wird auch auf zwei Seiten Gottes hingewiesen: Er ist einerseits barmherzig und gütig, anderseits aber „regiert“ (mālik) er am „Tag des Gerichts“ - er hat also eine „strenge“ Seite, ist ein Gott, den der Mensch, auch der Gläubige, fürchten muss. ${ }^{6}$ Die Gläubigen bitten Gott um Hilfe $(1,5)$; die Hilfe oder Gnade Gottes lässt, so erklärt der bedeutende Korankommentator aț-Ṭabarī (gest. 923) diese Aussage der Fātiḥa, die gute Handlung des Menschen gelingen, die er durch sein Handlungsvermögen und seine Wahl ausführt und die ihn den ,geraden Weg“ (aṣ-ṣirạt al-mustaqīm) gehen lässt. ${ }^{7}$ Das Wort șirāt, „Weg“, das letztlich auf den lateinischen Begriff (via) strata (davon „Straße“) zurückgeht, wird im Koran auch in nichtreligiösen Kontexten verwendet. ${ }^{8}$ Als religiös konnotierter Begriff erscheint es ferner in der islamischen Eschatologie, in Zusammenhang mit den Vorstellungen vom Jüngsten Ge-

5 Habib Hassan Touma, Die Musik der Araber (Taschenbücher zur Musikwissenschaft 37). Wilhelmshaven 1989, S. 189.

6 Die Wurzeln dieser Zweiteilung von Gottes Eigenschaften in Güte und Strenge scheinen in der Spätantike zu liegen. Besondere Bedeutung erlangt sie in der islamischen Mystik, wo die Polarität in die Begriffe ğamāl („Freundlichkeit“) und ğalāl (,Erhabenheit“) gefasst wird; vgl. dazu Die Fawā' iḥ al-ğamāl waFawātiḥ al-ğalāl des Nağm ad-Dīn al-Kubrā. Eine Darstellung mystischer Erfahrungen im Islam aus der Zeit um 1200 n. Chr. Hrsg. u. erl. v. Fritz Meier (Veröffentlichungen der Orientalischen Kommisssion / Akademie der Wissenschaften und der Literatur 9). Wiesbaden 1957, S. 79-82.

7 Cornelia Schöck, Auslegung durch Überlieferung und Theologie im Korankommentar des Muhammad b. Ğarīr aț-Ṭabarī (gest. 310/923). In: Michael Quisinsky u. Peter Walter (Hgg.), Kommentarkulturen. Die Auslegung zentraler Texte der Weltreligionen. Ein vergleichender Überblick (Menschen und Kulturen 3). Köln, Weimar, Wien 2007, S. 49-67, hier S. 59 f.

8 Dies zeigt Walid A. Saleh, The Etymological Fallacy and Qur'anic studies. Muhammad, Paradise, and Late Antiquity. In: Angelika Neuwirth, Nicolai Sinai u. Michael Marx (Hgg.), The Qur'ān in Context. Historical and Literary Investigations into the Qur'ānic Milieu (Texts and studies on the Qur'ān 6). Leiden, Boston 2010, S. 649-694, hier S. 665 auf. Er widerlegt somit Michael Cook, Der Koran. Eine kurze 
richt: Aṣ-Șirāt heißt die haardünne und messerscharfe Brücke, die die Menschen am Gerichtstag überschreiten müssen. Wer die Prüfung besteht, geht ins Paradies ein; wer zur Verdammnis bestimmt ist, stürzt hinunter in die Hölle. ${ }^{9}$

Die Fātiha leitet den Koran ein, ihr folgen die übrigen Suren weitgehend nach dem Einteilungsprinzip der absteigenden Länge. Sure 2 ist mit 286 Versen die längste Sure des Korans, die Suren 108 und 110 sind mit je drei Versen die kürzesten - die Abfolge der Suren im Koran ist also nicht chronologisch. ${ }^{10}$

Das arabische Wort qur'ān bedeutet „(liturgischer) Lesetext“, „Lektionar“ und ist vermutlich aus dem syrischen Wort qeryānā mit ähnlichem Sinn abgeleitet. ${ }^{11}$ Es handelt sich also um einen Text, der eine Funktion in der Liturgie der Gemeinde hatte, der ,,vorgetragen“ wurde. Gewöhnlich ist mit dem Wort „Koran“ der gesamte heilige Offenbarungstext gemeint, doch gibt es auch einzelne Stellen im Koran, die eher die Bedeutung „Rezitation“ oder „Vortrag“ nahelegen. Neben „Koran“ gibt es auch eine Reihe weiterer Bezeichnungen für den heiligen Offenbarungstext: „das Buch“ (al-kitāa) oder auch „das Buch Gottes“ (kitāb Allāh) oder etwa, bezogen auf die äußere Form, „Codex“ (d.h. ein Buch zwischen zwei Deckeln, muṣhaf). ${ }^{12}$

Auch wenn die Suren des Korans nicht chronologisch angeordnet sind, unterscheidet die islamische Tradition die Suren nach einem chronologischen Gesichtspunkt, indem sie von ,mekkanischen“ und „medinischen“ Suren spricht, d. h. Suren, die in Mekka, und solche, die in Medina offenbart wurden (in gedruckten Koranausgaben werden die Surenüberschriften jeweils entsprechend gekennzeichnet). ${ }^{13}$ Die Scheidegrenze ist $622 \mathrm{n}$. Chr., das Jahr, in dem die Hiğra, d.h. die Auswanderung Mohammeds von Mekka nach Medina, stattfand, und das den Beginn der islamischen Zeitrechnung markiert. „Mekkanische“ sind vor, „medinische“ nach der Hiğra offenbarte Suren. Bei einzelnen Suren lässt sich erkennen, dass sie aus verschiedenen kürzeren Texten zusammengesetzt sind, eine Tatsache, der sich die islamische Tradition sehr wohl bewusst ist. So können mekkanische Suren auch einzelne medinische Verse enthalten und umgekehrt medinische Suren einzelne mekkanische Verse. Da manche der frühen, mekkanischen Suren aus kurzen Texteinheiten beste-

Einführung. Stuttgart 2002, S. 18, der nur von einem religiösen Kontext ausgeht. Falsch ist auch Cooks Annahme, dass im Arabischen kein Plural zu șirăt gebildet worden sei, worin sich die Vorstellung ausdrücke, dass es nur einen richtigen Weg gebe; der Plural zu șirāt lautet șuruț (Saleh, S. 668).

9 Diese Vorstellung geht auf den zoroastrischen eschatologischen Mythos von der Činvad-Brücke zurück, die Diesseits und Jenseits verbindet und von den Seelen der Abgeschiedenen überquert werden muss; vgl. zum iranischen Kontext Aḥmad Tafażżolī, Činwad Puhl. In: Encyclopaedia Iranica. Bd. 5 (1992), S. $594 \mathrm{f}$.

10 Das Prinzip, einen in Kapitel gegliederten Text nach absteigender Länge der Kapitel zu ordnen, war auch von jüdischen Gelehrten bei der Einteilung der Mišna angewandt worden; dies hebt Gregor Schoeler, The Codification of the Qur'an. A Comment on the Hypotheses of Burton and Wansbrough. In: Neuwirth, Sinai u. Marx (Anm. 8), S. 779-794, hier S. 785, Anm. 29 hervor.

11 Was aber nicht heißt, dass es eine reale syrische Vorbildschrift für den Koran gegeben hätte; vgl. Neuwirth (Anm. 1), S. 102.

12 Vgl. Hartmut Bobzin, Der Koran. Eine Einführung. 4. Aufl. München 2001, S. 18; dabei sind die beiden Manifestationen des Korans als schriftlich fixierter Text (muṣhaf) und mündlicher Vortrag (qur'ān) deutlich zu unterscheiden; dazu Neuwirth (Anm. 1), S. 121.

13 Die Zuordnung einer jeden Sure als ganz oder partiell mekkanisch bzw. medinisch erscheint schon in alten Koranhandschriften; Angelika Neuwirth, Koran. In: Helmut Gätje (Hg.), Grundriss der arabischen Philologie. Bd. 2: Literaturwissenschaft. Wiesbaden 1987, S. 96-135, hier S. 99. 
hen, die Suren im Koran aber nach absteigender Länge geordnet sind, finden sich solche frühen Suren am Ende des Korans.

Inhaltlich-thematisch weisen mekkanische und medinische Suren markante Unterschiede auf. In den mekkanischen Suren herrschen Mahnung und Warnung vor sowie die Aufforderung zum Glauben. Wichtige Themen sind Gottes Allmacht und das Jüngste Gericht. Früh in der koranischen Offenbarung tauchen auch biblische Überlieferungen auf und die sog. Straflegenden, ${ }^{14}$ z. B. die Sintflutgeschichte. Für die späteren, medinischen Suren dagegen charakteristisch sind gesetzliche Bestimmungen, die das Leben der einzelnen Gläubigen und der Gemeinde regeln. Weitere wichtige Themen späterer Offenbarungen sind die Festlegung der religiösen Pflichten und Strafen für gewisse Vergehen. In diesen Akzentverschiebungen reflektiert sich der Werdegang Mohammeds, der in Mekka ausschließlich Prophet gewesen war, während in Medina die Funktion des Oberhaupts an der Spitze der jungen Gemeinde neben die prophetische Sendung trat; ferner weisen sie auch auf die mit dem Verkündigungsprozess parallel laufende Herausbildung einer Glaubensgemeinde mit einem eigenen Kultus hin.

Einige formale und inhaltliche Merkmale früher Suren seien im Folgenden durch Beispiele veranschaulicht. So lautet der Beginn der Sure al-Infițār („Die Spaltung“, Sure 82):

1 id

2 wa-idāa l-kawākibu ntatarat

3 wa-idāa l-bihāaru fuğğirat

4 wa-idā l-qubūru bu 'tirat

5 'alimat nafsun mā qaddamat wa-ahharat
Wann die Himmel zerkloben sind,

Und die Sterne zerstoben sind,

Wann die Meere sind verschäumt,

Und die Gräber sind geräumt;

Wird eine Seele wissen, was sie hat gethan und was versäumt.

Auf formaler Ebene fällt die Gliederung in kurze Sequenzen auf, die durch starke Rhythmisierung gekennzeichnet sind. Die einzelnen Sequenzen sind überdies gleich strukturiert Subjekt und Prädikat im Passiv oder dem VII. arabischen Verbalstamm, der passive Funktion hat, eingeleitet durch die Konjunktion $i \underline{d} \bar{a}$, „wenn“; es liegt die rhetorische Figur des „Isokolon“ (arab. muwāzana) vor. Von geradezu suggestiver Kraft ist die Aufsparung des Hauptsatzes auf die letzte Zeile der Sequenz, in der sich die emotionale Spannung entlädt.

Geschildert wird in diesem Surenanfang das Ende der Zeiten, das dem Jüngsten Gericht vorangeht. In eindrücklichen Bildern wird der Zerfall der kosmischen Ordnung beschrieben. Eine wichtige Rolle spielen dabei die translunaren Naturphänomene, die gleich zu Beginn genannt werden (Himmel, Sterne). Als Zeichen göttlicher Ordnung scheinen sie unverrückbar, ihre Zerstörung ist daher ein untrügliches Zeichen der Apokalypse. Eine ähnliche Bildwelt evoziert der Beginn der Sure at-Takwīr („Das Einhüllen“, Sure 81):

1 id̄ā $\check{s}$-šamsu kuwwirat

2 wa-id̄a n-nuğūmu nkadarat

3 wa-idā l-ǧibālu suyyirat $[\ldots]$

4 'alimat nafsun mā aḥ̣arat
Wann die Sonne sich wird ballen,

Die Sterne zu Boden fallen,

Und die Gebirge wallen, [...]

Wird eine Seele wissen was sie dargebracht.

14 Vgl. Bobzin (Anm. 12), S. 46-50. Zu den außerkoranischen Bezügen des Topos der „Straflegende“ vgl. Neuwirth (Anm. 1), S. 617-620. 
Wieder werden zuerst Himmelsphänomene (Sonne, Sterne) genannt, die ihre eigentliche Funktion als Zeichen göttlicher Ordnung verlieren. Was Rückert mit „ballen“ übersetzt, ist eine Passivform des II. arabischen Verbalstamms und bedeutet wörtlich ,zusammengerollt werden". ${ }^{15}$ Legt man die Vorstellung von der Sonne als einer Scheibe zugrunde, ist dies ein Bild von atemberaubender Anschaulichkeit - es taucht übrigens ähnlich, wenn auch mit einem Vergleich verbunden, in Kapitel 6, Vers 12-14 der Offenbarung des Johannes in Zusammenhang mit dem Himmel auf:

... da entstand ein großes Erdbeben, und die Sonne wurde schwarz wie ein härenes Trauergewand, und der ganze Mond wurde wie Blut, und die Sterne des Himmels fielen auf die Erde, wie ein Feigenbaum seine Früchte abwirft, wenn er von einem starken Wind geschüttelt wird, und der Himmel entschwand wie eine Buchrolle, die sich zusammenrollt, und alle Berge und Inseln wurden von ihren Stellen gerückt. ${ }^{16}$

Die Macht solcher bildhaft die Schrecken der Endzeit schildernder Worte ist unmittelbar evident. Werden sie außerdem von einem professionellen Rezitator vorgetragen, der über eine klangvolle Stimme oft in verhältnismäßig hoher Tonlage verfügt, wirken sie außerordentlich auf eine empfängliche Zuhörerschaft. In islamischen Quellentexten der vormodernen Zeit gibt es denn auch zahlreiche Berichte über Fromme, die durch das Lesen oder Hören eines Koranverses in Angst gerieten, weinten, ohnmächtig wurden oder gar starben. Noch Ibn Bațtūṭa, der berühmte Reisende des 14. Jahrhunderts, hat solche Szenen in Predigtversammlungen erlebt. ${ }^{17}$

Ein wichtiges Thema früher Suren ist auch die Aufforderung zum Glauben. Als monotheistisches Bekenntnis am prägnantesten ist sie ausgesprochen in der Sure al-Ihlāṣ (Sure 112):

1 qul huwa llāhu ahad

2 Allāhu ș-șamad

3 lam yalid wa-lam yūlad

4 wa-lam yakun lahu kufuwwan ahad
Sprich: Gott ist Einer,

Ein ewig reiner,

Hat nicht gezeugt und ihn gezeugt hat keiner

Und nicht ihm gleich ist einer.

Die formale Struktur der Sequenzen auch dieser Sure ist von hoher rhythmischer Stringenz und Einprägsamkeit. Besonders hervorzuheben ist das wirkungsvolle Wortspiel yalid / y $\bar{u}$ lad, das die zentrale Aussage von Gottes Einssein verdeutlicht. Die Aufforderung „sprich“ $(q u l)$ richtet sich zunächst wohl an den Verkünder, dann aber an jeden Gläubigen, der sich durch sie zum Monotheismus, zum tawhìd, bekennt. In wenigen Worten legt Sure 112 den Kern des tawhìd dar. Ihre identitätsstiftende Bedeutung für die frühe islamische Glaubensgemeinschaft belegt die Tatsache, dass sie auf den ersten einsprachig arabisch beschrifteten Münzen zu lesen ist, die der umayyadische Kalif 'Abdalmalik (reg. 685-705) prägen ließ,

15 Vgl. Manfred Ullmann (Hg.), Wörterbuch der klassischen arabischen Sprache (WKAS). Wiesbaden 1970 -2009 , sub voce.

16 Übersetzung der Zürcher Bibel; zitiert ist die Ausgabe: Die Heilige Schrift des Alten und des Neuen Testaments. 18. Aufl. Zürich 1982. Die Ähnlichkeit der koranischen Schilderungen der Apokalypse mit der Bildwelt der jüdisch-christlichen Eschatologie betont auch Bobzin (Anm. 12), S. 37.

17 Hellmut Ritter, Das Meer der Seele. Mensch, Welt und Gott in den Geschichten des Farīduddīn 'Ațtār. Leiden 1978, S. $136 \mathrm{f}$. 
was sie zu einem der ältesten schriftlich bezeugten Korantexte überhaupt macht. ${ }^{18}$ Vers 3 ist wohl als Abgrenzung gegen die christliche Trinitätslehre zu verstehen: Gott hat keinen Sohn gezeugt und ist auch kein Sohn. ${ }^{19}$

Sowohl auf formaler als auch auf inhaltlich-thematischer Ebene unterscheiden sich die späteren medinischen Suren markant von den früheren mekkanischen. Als Beispiel einer späten Offenbarung sei Sure 2, Vers 185 angeführt:

Der Monat Ramadan, in dem herabkam der Koran

Den Menschen als Geleit

Und als Beweis für das Geleit und die Entscheidung -

Wer in ihm zugegen ist, soll in ihm fasten,

doch wer von euch erkrankt oder auf Reisen ist,

für den ist eine Anzahl anderer Tage möglich.

Gott will für euch das Leichte (yurīdu llāhu bikum ul-yusra),

das Schwere will er nicht für euch (wa-lā yurīdu bikum ul- 'usra).

Die Zahl sollt ihr erfüllen

Und Gott dafür rühmen, dass er euch geleitet hat.

Vielleicht seid ihr ja dankbar (wa-la'allakum taškurūn). ${ }^{20}$

Zunächst fällt die Länge dieses Verses auf - er übertrifft an Umfang manche der frühen Suren. Es gibt in ihm, abgesehen von dem Binnenreim yusra / 'usra, nur ein Reimwort das letzte Wort des Verses (taškurūn), es reimt auf das letzte Wort des vorhergehenden Verses 184 (ta lamün). Inhaltlich geht es an dieser Stelle nicht um die Weckung von Emotionen, entsprechend wird auch auf die Verwendung von bildlicher Sprache verzichtet. Essentiell ist aber die Festlegung einer zentralen religiösen Vorschrift, hier des Ramadanfastens, im Rahmen der Ordnung für die islamische Urgemeinde.

\section{Aspekte der koranischen Textgeschichte und Rezeption}

Der Prozess der Verschriftlichung der durch den Propheten Mohammed empfangenen und mündlich verkündeten Offenbarung hat früh eingesetzt - auch die Bezeichnung kitāb, „Buch“, für den Koran weist darauf hin -, doch lag der Koran unmittelbar nach dem Tod des Propheten (632 n. Chr.) nicht als vollständiges, schriftliches Corpus vor. Die weitere Überlieferung der Offenbarung vollzog sich sowohl mündlich als auch schriftlich; das primäre Medium war dabei die mündliche Überlieferung, während die schriftliche hauptsächlich die Funktion einer Gedächtnisstütze hatte (wie auch in anderen kulturellen Traditionen des Vorderen Orients). ${ }^{21}$ Es gab Personen, die Teile der koranischen Verkündigung auswendig kannten, es gab auch schriftliche Aufzeichnungen auf unterschiedlichen Materia-

18 Bobzin (Anm. 12), S. 56 f.

19 Zur koranischen Auffassung von Maria und Jesus vgl. Neuwirth (Anm. 1), S. 472-489.

20 Deutsche Übersetzung von Hartmut und Katharina Bobzin.

21 Zu diesen zwei Arten der „Veröffentlichung“ des Korans vgl. Gregor Schoeler, Schreiben und Veröffentlichen. Zu Verwendung und Funktion der Schrift in den ersten islamischen Jahrhunderten. Der Islam 69 (1992), S. 1-43. 
lien: Papyrus- und Pergamentstücke - das Papier war damals im Vorderen Orient noch nicht bekannt - Palmstengel, Tonscherben, Lederfetzen oder auch Kamelknochen. ${ }^{22}$ Nach traditionell islamischer Auffassung, der auch die moderne Koranforschung weitgehend folgt, veranlasste der dritte Kalif 'Utmān (reg. 644-656) etwa zwanzig Jahre nach dem Tod des Propheten eine systematische Sammlung und Redaktion des vorhandenen Materials und die Zusammenstellung zu einem Codex durch eine Kommission, die unter der Leitung von Mohammeds Sekretär Zayd b. Tāait stand. Nach Vollendung dieser Arbeit wurde je ein Exemplar des nun verbindlichen Textes in die Zentren der frühen islamischen Welt geschickt: nach Mekka, Medina und Damaskus sowie in die arabischen Metropolen des Irak, Bașra und Kūfa. Andere Handschriften sollten nach der Anordnung 'Uțāns vernichtet werden, ${ }^{23}$ was sich allerdings erst während eines länger dauernden Prozesses vollzog. Die endgültige Etablierung eines autoritativen Textes erfolgte höchstwahrscheinlich in der Zeit des Umayyadenkalifen 'Abdalmalik (reg. 685-705), sie kam also, wenn man mit den monotheistischen Nachbarreligionen vergleicht, in einer viel kürzeren Zeit zustande als die kanonischen Corpora des Alten und des Neuen Testaments. ${ }^{24}$ Die frühe Redaktion des Korans hat zu einer weitgehend einheitlichen Überlieferung des Textes geführt. Fast alle heute erscheinenden Drucke des Korantextes folgen der sogenannten ,ägyptischen Standard-“ oder „Kairiner Version“, die 1923 auf Veranlassung des damaligen Königs Fu'ād von Gelehrten der Azhar-Hochschule veröffentlicht wurde und auf der irakischen Textüberlieferung fußt. In den Maghreb-Staaten erscheinende Koranausgaben beruhen dagegen auf der Lesetradition von Medina. ${ }^{25}$ Allerdings ist anzumerken, dass in Kreisen der Schia lange bezweifelt wurde, dass der existierende Korantext tatsächlich der „wahre“ Koran sei; der wahre Text sei vielmehr von 'Alī (gest. 661), dem vierten rechtgeleiteten Kalifen und ersten schiitischen Imam, gesammelt, danach aber von seinen Gegnern verfälscht worden; man habe insbesondere Passagen, aus denen eine Vorrangsstellung 'Alīs herauszulesen war, unterdrückt. Diese Auffassung einer sunnitischen Koranfälschung (tahrīf al-qur'ān) wurde in der Schia bis ins 10. Jahrhundert mehrheitlich vertreten, hat danach aber stark an Bedeutung verloren. Dass sie nie ganz aufgegeben wurde, zeigt eine noch im 20. Jahrhundert geführte Debatte über den tahrīf. ${ }^{26}$

Trotz der frühen Verschriftlichung des Korans stellte sich bei der Etablierung eines autoritativen Textes ein besonderes Problem: die damalige Mehrdeutigkeit der arabischen Schrift. Zwar wurden bereits im 7. Jahrhundert diakritische Zeichen zur Markierung homographer Buchstaben benutzt. ${ }^{27}$ Ihre Anwendung geschah jedoch noch nicht konsequent. Weil Fehlschreibung (tașhīf) das rechte Verständnis der heiligen Offenbarungsschrift bedrohte, wurde eine Orthographiereform durchgeführt, die vermutlich durch den Umayyadenkalifen 'Abdalmalik initiiert und unter der Aufsicht des Gouverneurs al-Hağğāğ b. Yū-

22 Zu den Materialien und ihren arabischen Bezeichnungen vgl. Schoeler (Anm. 10), S. $781 \mathrm{f}$.

23 Bobzin (Anm. 12), S. 102.

24 Neuwirth (Anm. 1), S. 29. Zur Herausbildung des biblischen Kanons vgl. den Beitrag von Jörg Frey in diesem Band.

$25 \mathrm{Zu}$ den beiden Lesetraditionen vgl. Bobzin (Anm. 12), S. $104 \mathrm{f}$.

26 Zum gesamten Themenkomplex vgl. die exzellente Studie von Rainer Brunner, Die Schia und die Koranfälschung (Abhandlungen für die Kunde des Morgenlandes 53). Würzburg 2001.

27 Gerhard Endress, Die arabische Schrift. In: Wolfdietrich Fischer (Hg.), Grundriss der arabischen Philologie. Bd. 1: Sprachwissenschaft. Wiesbaden 1982, S. 165-197, hier S. 175. 
suf (gest. 713) umgesetzt wurde. Sie betraf insbesondere die diakritische Unterscheidung von Konsonanten. ${ }^{28}$ Eine Vokalisierung des Korantextes erfolgte erst seit Ende des 8. Jahrhunderts und zunächst nur bei Wörtern mit konkurrierenden Aussprachemöglichkeiten. ${ }^{29}$

Da verschiedene diakritische Punktierung eines Buchstabens der arabischen Schrift ganz andere Wörter hervorbringt, kann sich dadurch der Sinn ganzer Textpassagen ändern. In jüngerer Zeit hat sich des Verfahrens, Wörter des Korantextes umzupunktieren, um dadurch die „ursprüngliche“ Lesart wieder freizulegen, Christoph LuXENBERG in allerdings willkürlicher und philologisch unhaltbarer Weise bedient. Er versuchte dadurch, seine Theorie einer ,syroaramäischen“ Lesart des Korans zu stützen. ${ }^{30}$ Es hat aber wohl einzelne Stellen im Koran gegeben, bei denen schließlich nicht die ursprüngliche Lesart eines Wortes in den autoritativen Text aufgenommen wurde. Ein Beispiel, bei dem dies der Fall gewesen sein könnte und auf das im Folgenden kurz eingegangen sei, stellt der Hund der Siebenschläfer dar.

Auf die Legende von den Siebenschläfern wird in Sure 18, 9-26 angespielt. Sie ist zentral für die Thematik der Sure, wie auch aus deren Titel al-Kahf („Die Höhle“) hervorgeht. Zugrunde liegt eine Erzählung christlichen Ursprungs. Ihr Inhalt ist, kurz zusammengefasst, folgender: Der römische Kaiser Decius (reg. 249-251) verfolgte die Christen in Kleinasien. Sieben junge Männer, Söhne christlicher Notabler von Ephesos, entziehen sich dem Zwang, ihrem Glauben abzuschwören, durch Flucht in eine Höhle am Berg Anchylos. Dort schlafen sie ein. Wie die Häscher des Decius sie finden, werden sie lebendig eingemauert. Statt zu verhungern, schlafen sie weiter und erwachen erst viele Jahre später in der Regierungszeit des christlichen Kaisers Theodosius II. (reg. 408-450) wieder. Einer von ihnen geht in die Stadt, um etwas zu essen zu kaufen. Die Stadt aber erscheint ihm fremd. Überall sieht er die Zeichen des Christentums. Wie er Brot kaufen und mit einem Geldstück aus der Zeit des Decius bezahlen will, hält man ihn für einen Betrüger, der einen alten Schatz gefunden hat. Die Geschichte, die er erzählt, glaubt man nicht und führt ihn gefesselt zum Statthalter und zum Bischof. Gemeinsam gehen sie zur Höhle und finden alles so vor, wie es der junge Mann beschrieben hat. Kaiser Theodosius erfährt davon und ist sehr erfreut, weil in seiner Regierungszeit viele Christen nicht mehr an die Auferstehung von Leib und Seele glauben. Die Siebenschläfer sind ihm nun der Gegenbeweis. Theodosius sucht sie auf, sie segnen ihn und entschlafen danach für immer. ${ }^{31}$

Im Koran heißen die Siebenschläfer așhāb al-kahf („Gefährten der Höhle“). Mehrere Besonderheiten werden bei der koranischen Wiedergabe der Legende erwähnt, so der rätselhafte Begriff ar-raqim (Vers 9), der in der Kommentarliteratur verschieden gedeutet wurde; die Ausrichtung des Höhleneingangs auf das Sternbild des Großen Bären (Vers 17); die Tatsache, dass die Körper während des Schlafs nach rechts und nach links gewendet

28 Dazu Omar Hamdan, The Second Mașāhif Project. A Step towards the Canonization of the Qur'anic Text. In: Neuwirth, Sinai u. Marx (Anm. 8), S. 795-835, hier S. 807.

29 Neuwirth (Anm. 1), S. 106.

30 Für eine kritische Darstellung von Luxenbergs Methode vgl. Stefan Wild, Lost in Philology? Virgins of Paradise and the Luxenberg Hypothesis. In: Neuwirth, Sinai u. Marx (Anm. 8), S. 625-647, hier S. 634-640. Zu Luxenbergs Thesen vgl. auch unten, S. 43.

31 Nach Hermann Kandler, Die Bedeutung der Siebenschläfer (Așhāạ al-kahf) im Islam. Untersuchungen zu Legende und Kult in Schrifttum, Religion und Volksglauben unter besonderer Berücksichtigung der Siebenschläfer-Wallfahrt (Abhandlungen zur Geschichte der Geowissenschaften und Religion-UmweltForschung. Beiheft 7). Bochum 1994, S. 12 f. 
wurden, und der beim Eingang liegende Hund (Vers 18); sowie die Angabe, dass die Anzahl der Schläfer verschieden überliefert sei: drei, fünf oder sieben (bzw. mit ihrem Hund vier, sechs oder acht, Vers 22) - Gott allein aber wisse, wie viele es seien. Die Dauer des Schlafs wird mit 309 Jahren angegeben (Vers 25).

Dass die Siebenschläfer von einem Hund bewacht werden, wird so explizit erstmals im Koran erwähnt. ${ }^{32}$ Die älteste christliche Quelle, Jakob von Sarug (gest. 521), nennt einen Wächter oder Engel ( $\operatorname{c} r \bar{a}) .{ }^{33}$ Michael Huber wies darauf hin, dass ,bei den Qorânerklärern“" wiederholt das Wort kāli uhum, ,ihr Wächter" erscheine. ${ }^{34}$ Vielleicht hat auch tatsächlich ursprünglich im Text statt kalbuhum, „ihr Hund“, kāli'uhum, „ihr Wächter“, gestanden ${ }^{35}$ denn nach koranischer Orthographie, in der das lange $\bar{a}$ oft nicht markiert wird, ${ }^{36}$ sehen die beiden Wörter sehr ähnlich aus (كلبهم bzw. كلئهم). Lässt man überdies die diakritische Markierung der Konsonanten weg, sind sie nicht mehr voneinander zu unterscheiden, was eine Verwechslung noch wahrscheinlicher macht. Es hätte sich also ursprünglich nicht um einen Hund, sondern um einen Wächter gehandelt, der die Siebenschläfer behütete. ${ }^{37}$

Da aber die Lesung kalbuhum im autoritativen Text feststand, ist die spätere islamische Überlieferung stets von einem Hund ausgegangen. Ihm kam im Rahmen des Kultes, der sich im islamischen Volksglauben um die Siebenschläfer entwickelte, besondere Verehrung zu. So wurde er zu den auserwählten Tieren gezählt, die ins Paradies kommen - obwohl im Islam der Hund allgemein als unrein gilt. In nachkoranischer Überlieferung erhielt er den Namen Qițmīr und spielte - wie die Siebenschläfer überhaupt - eine wichtige Rolle im Amulettwesen. ${ }^{38}$ Auch bei Darstellungen der Siebenschläfer in der islamischen Buchmalerei fehlt der Hund in der Regel nicht.

Die Art und Weise, wie die Legende von den Siebenschläfern im Koran wiedergegeben wird, reflektiert übrigens in charakteristischer Weise den koranischen Umgang mit narrativen Texten, bei dem oft Anspielungen auf zentrale Elemente einer Geschichte vor einer linear fortlaufenden Erzählung von Anfang bis Ende der Vorzug gegeben wird. Dies mag mit der Intention des docere, der Belehrung, zusammenhängen, die im Koran mehr gewichtet wird als das delectare, die Unterhaltung. ${ }^{39}$ Möglicherweise war auch die allgemeine Verbreitung und Bekanntheit gewisser Erzählstoffe mit ein Grund, dass eine erneute Nach-

32 Ebd., S. 56; zum einzigen christlichen Text, der in Zusammenhang mit den Siebenschläfern möglicherweise einen Hund (catulus) nennt, vgl. ebd.

33 So nach der Textfassung bei Enrico Gismondi, Linguae Syriacae grammatica et chrestomathia cum glossario. Beirut 1900, S. 48. Zu den Handschriften und Editionen des syrischen Textes vgl. Michael Huber, Die Wanderlegende von den Siebenschläfern. Leipzig 1910, S. 1.

34 Huber (Anm. 33), S. 243. Leider gibt Huber keine Quellen für diese Aussage an. In aț-Ṭabarīs Korankommentar wird der Begriff kāli', bezogen auf Sure 18, Vers 18 bzw. 22, nicht erwähnt.

35 Davon geht auch Wolfram Waldner, Wie kam der Hund in die Siebenschläferlegende? In: Otto Jastrow, Shabo Talay u. Herta Hafenrichter (Hgg.), Studien zur Semitistik und Arabistik. Festschrift für Hartmut Bobzin. Wiesbaden 2008, S. 423-430, hier S. 427 aus.

36 Vgl. Theodor Nöldeke, Geschichte des Qorāns. Bd. 3: Gotthelf Bergsträsser u. Otto Pretzl, Die Geschichte des Korantexts. 2., völlig umgearb. Aufl. Leipzig 1938, S. 31-33.

37 Das Wort kăli' kommt im Koran sonst nicht vor, ist aber anderwärts gut bezeugt, u. a. in der altarabischen Poesie; vgl. Ullmann, WKAS (Anm. 15), sub voce.

38 Kandler (Anm. 31), S. 117. Während die Namen der Männer oft in einer verballhornten Form vorliegen, wird der Name des Hundes immer korrekt wiedergegeben.

39 Vgl. Neuwirth (Anm. 1), S. 605. 
erzählung gar nicht als notwendig erachtet wurde; die Anspielung genügte den Hörern, assoziativ die fehlenden Teile der Geschichte zu ergänzen.

Die Etablierung des autoritativen Korantextes vollzog sich, wie erwähnt, in umayyadischer Zeit; seine frühe Formung dagegen begann bereits mit dem Beginn der Verkündigung, der auf ungefähr das Jahr 610 anzusetzen ist. Ein wichtiger Akteur in dieser Phase der Konstitution des Textes ist die Gemeinde, an die Mohammed die Verkündigung seiner Botschaft richtete. Der Text des Korans reflektiert und dokumentiert dabei die Diskussionen von Leitgedanken der sich entwickelnden neuen Botschaft zwischen Verkünder und Gemeinde. Die Interaktion zwischen diesen beiden Polen ist ein wichtiges Thema der jüngsten Koranforschung, ebenso die Funktion der frühen (auch nachprophetischen) Gemeinde bei der Kanonisierung des Textes sowie die Frühgeschichte seiner Exegese. ${ }^{40}$

Die innerislamische Rezeption des Korans definiert sich durch seine Funktion in islamisch geprägten Gesellschaften, durch die Bedeutung, die ihm zukommt, den „Sitz im Leben", und auch durch den Umgang mit ihm. Drei wichtige Punkte seien dabei hervorgehoben: Der Koran ist heiliger Offenbarungstext; der Koran ist die erste Quelle der islamischen Rechtsfindung; der Koran ist nach islamischem Verständnis ein nicht nachahmbares sprachlich-literarisches Kunstwerk.

Als heiliger Offenbarungstext, als die „Gründungsurkunde“ ihrer Religion ist der Koran das wichtigste identitätsstiftende Moment, das alle Muslime der Welt miteinander verbindet. Ein Islam ohne Koran ist daher nicht denkbar, so wie ein Christentum ohne Jesus nicht denkbar ist. Nach islamischem Verständnis ist der Koran auch die letzte Offenbarung, die die Menschheit von Gott empfangen hat. Nach ihm wird es keine Offenbarung mehr geben. Die früheren Offenbarungsschriften (Tora, Evangelium) gehen zwar auf dieselbe himmlische Urschrift zurück wie der Koran, nur dieser aber repräsentiert die himmlische Urschrift unverfälscht und er „,bestätigt“ gleichzeitig die früheren Offenbarungsschriften.

Der Koran begleitet muslimische Gläubige im Alltag und in allen Phasen ihres Lebens. In liturgischem Kontext ist er an die arabische Sprache gebunden, d. h., er kann in gültiger Form nur auf Arabisch rezitiert werden. Dies betrifft auch seine Verwendung im Ritualgebet. Da die arabische Sprache jedoch für sehr viele Gläubige, die des Arabischen nicht mächtig sind, ein Hindernis zum Verständnis des Textes bedeutet, sind Übersetzungen des Korans in andere Sprachen als Hilfsmittel zugelassen; sie ersetzen aber den arabischen Text nicht. Die erste Sprache, in die der Koran übersetzt wurde, war das Persische. Die frühesten erhaltenen Zeugnisse gehen auf das 10. Jahrhundert zurück. ${ }^{41}$ In der Regel ging man bei der Erstellung von Manuskripten so vor, dass die persische Übersetzung zwischen die Zeilen des arabischen Grundtextes gesetzt wurde. Ein Beispiel einer solchen Interlinearübersetzung gibt die auf das Jahr 1212 der islamischen Zeitrechnung (= 1798/99 n. Chr.) datierte Koranhandschrift M III 157 der Basler Universitätsbibliothek (Abb. 1). ${ }^{42}$ Den Übersetzungen ins Persische folgten Übersetzungen des Korans in die meisten Sprachen

40 Man vergleiche z. B. die Studie von Nicolai Sinai, Fortschreibung und Auslegung. Studien zur frühen Koraninterpretation (Diskurse der Arabistik 16). Wiesbaden 2009.

41 Travis Zadeh, The Vernacular Qur'an. Translation and the Rise of Persian Exegesis (Qur'anic studies series 7). Oxford 2012, S. 267.

42 Die Abbildung zeigt den Beginn der Sure at-Takwīr (Sure 81). Der arabische Grundtext erscheint im Original schwarz, die persische Übersetzung rot und in anderem Duktus (Nasta 'īq) darunter. Der ara- 


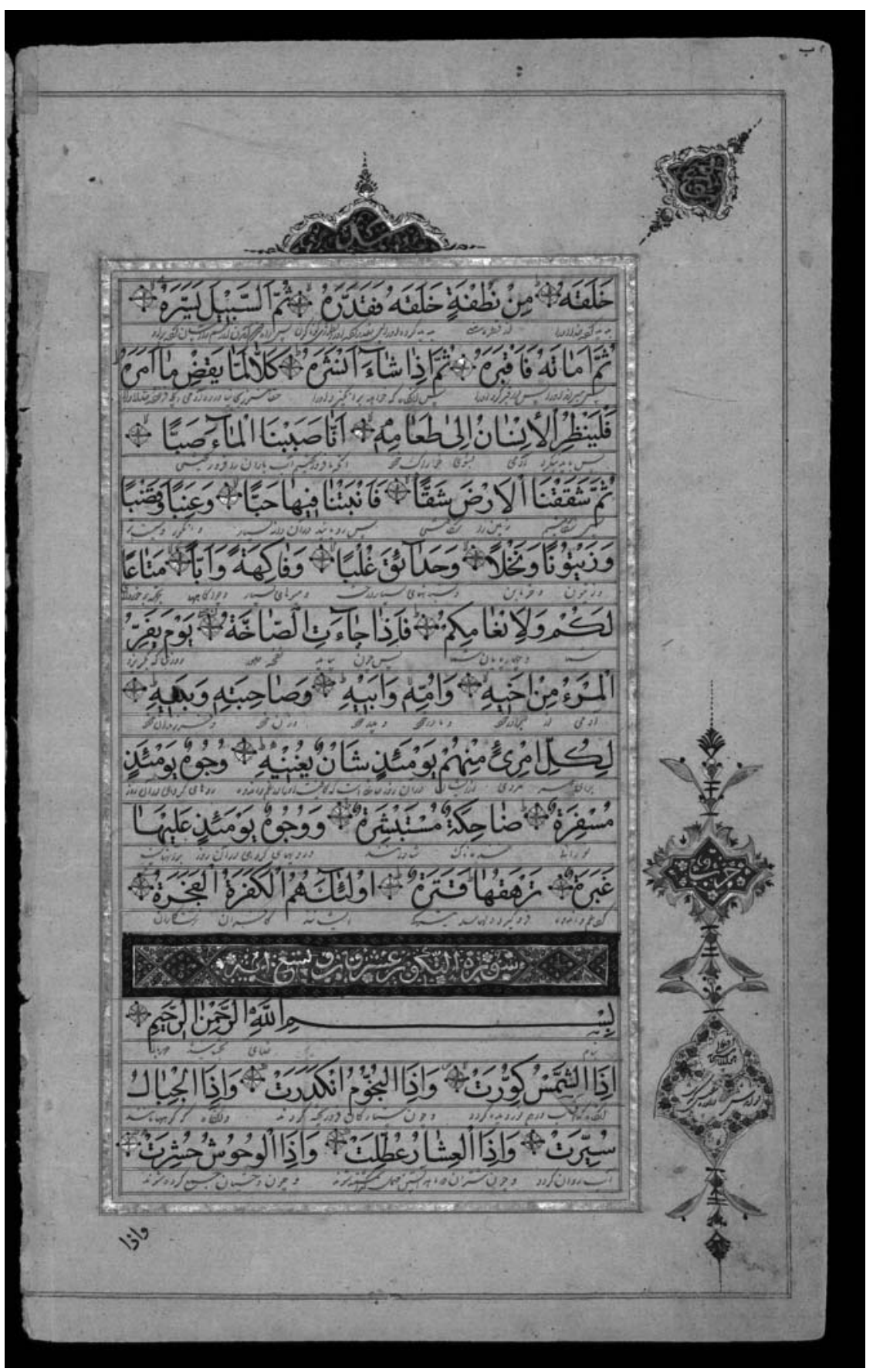

Abb. 1: Koranhandschrift mit arabischem Grundtext und persischer Übersetzung (1212 bzw. 1798/99), Beginn von Sure 81 - Basel, Universitätsbibliothek, M III 157, fol. 291 - (C) Universitätsbibliothek Basel 
der Welt, und heute eröffnen die elektronischen Medien ganz neue Möglichkeiten der mehrsprachigen Präsentation des Korans; so kann man Text bzw. Übersetzung gleichzeitig lesen und hören, wobei für die arabische Audiofassung oft zwischen mehreren berühmten Koranrezitatoren gewählt werden kann.

Durch eine Übersetzung konnte den nicht des Arabischen mächtigen Gläubigen der heilige Text erschlossen werden. Das rechte Verständnis des Textsinns war aber auch im arabischen Original nicht überall selbstverständlich; daher begann sich schon früh in der Geschichte des Islams und in Zusammenhang mit der Kanonisierung des Textes eine Kommentarliteratur zum Koran zu entwickeln, die sich in der Folge reich entfalten sollte. Auf unklare Passagen verweist übrigens schon der Koran selbst, wenn etwa in Sure 3, Vers 7 zwischen „,deutlichen“ (muḥkamāt) und „mehrdeutigen“ (mutašābihāt) Versen unterschieden wird. ${ }^{43}$ Im Lauf der Jahrhunderte bildete sich eine eigentliche Koranphilologie heraus, in Wechselwirkung mit ihr entstanden mehrere Richtungen der Korandeutung, in denen sich verschiedene religiöse Orientierungen widerspiegelten. So gab es Exegeten, die eine Kommentierung des Korantextes strikt auf dessen äußeren Wortlaut beschränkten, andere, die versuchten, einen verborgenen ,inneren Sinn“ aus dem Text herauszudeuten. Als sich im 19. Jahrhundert die islamische Welt mit dem naturwissenschaftlichen und technologischen Fortschritt des Westens sowie der dadurch bedingten Änderung des Weltbildes konfrontiert sah, begegneten modernistische Theologen dieser Herausforderung, indem sie postulierten, dass neue naturwissenschaftliche Erkenntnisse im Koran bereits immanent vorhanden seien. Führend in dieser Richtung der Koranexegese waren der ägyptische Reformtheologe Muhammad 'ABDuH (1849-1905) und sein Schüler Muhammad RAŠīD RIḌĀ (1865-1935). Ihr Korankommentar, ab der Wende zum 20. Jahrhundert in der Zeitschrift al-Manār (,Der Leuchtturm“) publiziert, gilt als der erste moderne Korankommentar überhaupt. Ägypten blieb auch weiterhin führend in der Entwicklung neuer koranexegetischer Ansätze. In den 1940er Jahren erklärte der Literaturwissenschaftler Amīn AL-HūLĪ (gest. 1966), dass der Koran als bedeutendstes Buch in arabischer Sprache zuerst einmal als literarischer Text zu verstehen und mittels der auch sonst in der Literaturwissenschaft anerkannten Methoden zu erforschen sei. Hūūīs „literarische Exegese“ (tafsīr adabī) wurde von seiner Frau, der Arabistikprofessorin ' $\bar{A}$ 'iša 'ABDARRAHMĀN (Bint aš-Šătii', gest. 1999), und einigen seiner Schüler weiterentwickelt. ${ }^{44}$ Auf Hūūīs Methodik fußt auch Nașr Ḥāmid ABū ZAYD (gest. 2010), der das Konzept vom Koran als einem literarischen Werk mit einem kommunikationstheoretischen Modell für das Verständnis des Offenbarungsvorgangs verband. ${ }^{45}$ Abū ZAYD plädierte ferner für eine historische Kontextualisierung des

bische Surenanfang $\underline{i} \underline{d} \bar{a} \check{s}$-šamsu kuwwirat wird persisch mit āngāh ki äftāb dar ham nawardīda gardad wiedergegeben. Das hierarchische Gefälle zwischen Original und Übersetzung ist durch die verschiedene Schriftgröße markiert. Zum Beginn von Sure 81 vgl. auch oben, S. 31.

43 Bobzin (Anm. 12), S. $109 \mathrm{f}$.

44 Rotraud Wielandt, Wurzeln der Schwierigkeit innerislamischen Gesprächs über neue hermeneutische Zugänge zum Korantext. In: Stefan Wild (Hg.), The Qur'an as text (Islamic philosophy, theology and science 27). Leiden, New York, Köln 1996, S. 257-282, hier S. 258; vgl. auch Neuwirth (Anm. 1), S. 114.

45 Wielandt (Anm. 44), S. 260. Zu Abū Zayds koranhermeneutischer Methode vgl. auch Navid Kermani, Offenbarung als Kommunikation. Das Konzept waḥy in Nașr Hāmid Abū Zayds Mafhūm an-nașṣ (Europäische Hochschulschriften. Reihe 27, Asiatische und afrikanische Studien 58). Frankfurt a. M. u. a. 1996. 
Korans: Es sei nicht so, „dass manche Verse des Korans eine ewige Sprache besitzen, die sich über alle Zeiten hinweg von selbst erklärt, während nur einige andere zeitgebunden sind. Nein, der gesamte Koran hat eine historische Dimension, die für sein korrektes Verständnis wichtig ist. “46

Mit seinen Thesen provozierte Nașr Hāamid ABŪ ZAYD bekanntlich das religiöse Establishment Ägyptens. Er wurde der Apostasie, also des Abfalls vom Islam, bezichtigt und musste das Land verlassen. Seine Forderung, den Koran als historischen Text zu verstehen, kollidierte mit einem Grundsatz, der seine Wurzeln in einer Debatte hat, die im 9. Jahrhundert unter islamischen Theologen mit aller Heftigkeit geführt wurde; der Streitpunkt war, ob der Koran geschaffen sei oder nicht. Durchgesetzt hatte sich damals die Meinung, dass der Koran nicht geschaffen, also ewig, sei - und dies gilt nach Auffassung der traditionellen Theologie grundsätzlich bis heute. Durch das Dogma seiner Ungeschaffenheit war der Koran aber historischer Verortung entzogen - und damit einem spezifischen historischen und gesellschaftlichen Kontext mit den entsprechenden Bedingtheiten. An der Auseinandersetzung um Naṣr Hāmid ABŪ ZAYDs hermeneutischen Zugang zum Koran zeigt sich somit nicht zuletzt der große Einfluss einer über Jahrhunderte gewachsenen, aufs engste mit dem Koran verknüpften, konservativen und dogmatisch verbindlichen Tradition.

Von seiner exklusiven Stellung als heiliger Offenbarungstext abgesehen, ist der Koran auch die erste Quelle der islamischen Rechtsfindung. Er ist aber kein geschlossenes Rechtswerk, kein Corpus iuris. Obwohl die späteren medinischen Suren viele rechtliche Dinge regeln, gibt der Koran nicht auf jede juristische Frage eine Antwort. Um die Lücken zu schließen, greift man daher auf andere schriftliche Quellen zurück. In erster Linie sind dies die in einer Spezialliteratur gesammelten Überlieferungen über die Aussprüche und Handlungen des Propheten Mohammed, die dem Koran an Autorität kaum nachstehen; diese Spezialliteratur wird, ebenso wie der jeweilige einzelne Ausspruch des Propheten, arabisch hadīt - wörtlich: „Erzählung“, „Geschichte“ - genannt.

Schließlich gilt der islamischen Tradition der Koran als unnachahmbares sprachlich-literarisches Kunstwerk. Dieses Dogma hat sich, wie Quellen bezeugen, im 10. Jahrhundert entwickelt. ${ }^{47}$ Mit „Unnachahmbarkeit“ ist nicht die Unnachahmbarkeit als heiliger Offenbarungstext gemeint - diese war ohnehin durch den Anspruch gegeben, dass im Koran die von Juden und Christen verfälschte „Urreligion“ wiederhergestellt sei und dass Gott im Koran zum letzten Mal vor dem Jüngsten Gericht zur Menschheit gesprochen habe - , unnachahmbar war der Koran gemäß dieser Auffassung auf der sprachlich-stilistischen Ebene, und als Bestätigungswunder der Prophetie Mohammeds machte er jeden möglichen Herausforderer unfähig, etwas Ähnliches zu vollbringen. Auch rückwirkend hob das Wunder des Korans Mohammed über alle früheren Propheten hinaus, die zwar ebenfalls Wunder getan hatten - Jesus zum Beispiel war heilkundig, Moses zauberkundig gewesen deren Wunder aber mit ihnen verschwunden waren. Diese „Unnachahmbarkeit“ des Korans

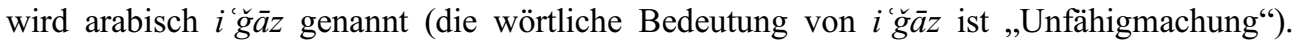
Der $i \stackrel{g}{g} \bar{a} z$ lieferte den vielleicht wichtigsten Anstoß zur endgültigen Ausbildung einer ara-

46 Nașr Hāmid Abū Zayd, Mohammed und die Zeichen Gottes. Der Koran und die Zukunft des Islam. Freiburg i. Br., Basel, Wien 2008, S. 21.

47 Meine Ausführungen fußen auf Angelika Neuwirth, Das islamische Dogma der „Unnachahmlichkeit des Korans“ in literaturwissenschaftlicher Sicht. Der Islam 60 (1983), S. 166-183. 
bischen Literaturtheorie. Dabei enthob die Tatsache, dass die Wunder der früheren Propheten, namentlich jene der beiden wichtigsten, Moses und Jesus, auf einer anderen als der sprachlichen Ebene lagen und nicht ihre Offenbarungsschriften (Tora, Evangelium) betrafen, die Befürworter dieser Unnachahmbarkeitstheorie von vornherein der Aufgabe, den Koran konkret mit den älteren Offenbarungsschriften zu vergleichen, um das $i$ ' $g \bar{a} z$-Dogma zu beweisen. Der Akzent bei der Diskussion über die Einzigartigkeit des Korans lag dabei hauptsächlich im Bereich des Stils: Wortfolge, Gebrauch der Wörter, Gebrauch von Metaphern und Redefiguren - all dies wurde, so wie es sich im Koran darstellte, als unübertroffen und unübertrefflich in seinem Grad der Eloquenz betrachtet.

Im Anschluss an die innerislamische Rezeption des Korans sei noch kurz die Geschichte seiner europäischen Wahrnehmung und Rezeption gestreift. Im europäischen Mittelalter interessierte man sich zunächst nur aus apologetischen Gründen für den Koran, wobei es hauptsächlich darum ging, ihn als „Lügenbuch“ zu entlarven. Den Vergleichsmaßstab bildete die Bibel - man bemerkte, dass Koran und Bibel gemeinsame Stoffe hatten, interpretierte von der Bibel abweichende Versionen im Koran jedoch als Entstellungen und versuchte, logische Widersprüche und Ungereimtheiten im Koran nachzuweisen. Die erste im Jahr 1143 abgeschlossene Koranübersetzung in eine westliche Sprache - ins Latein - war ausschließlich durch das Bestreben motiviert, dadurch Rüstzeug für die Bekämpfung des Islams, der damals meist als christliche Häresie verstanden wurde, zu erhalten; die apologetische Zuspitzung wird schon aus dem Titel deutlich, unter dem diese erste Koranübersetzung bekannt wurde: ,Lex Mahumet pseudoprophete‘. Den Auftrag dazu hatte der cluniazensische Abt Petrus Venerabilis gegeben, der nach dem Ausgang des ersten Kreuzzugs (1095-1099) zur Überzeugung gelangt war, dass der Islam nicht mit Waffengewalt, sondern nur mit der Macht des Wortes zu besiegen sei. Dies aber setzte die Kenntnis der Grundlehren des Islams, wie sie im Koran niedergelegt sind, voraus. Mit der Übersetzung wurde der englische Theologe und Mathematiker Robert von Ketton beauftragt, der sich dafür der Hilfe eines arabischen Muttersprachlers versicherte. ${ }^{48}$ Obwohl Roberts Übersetzung viele Mängel aufwies, blieb sie länger als ein halbes Jahrtausend die wichtigste Quelle für die Korankenntnis im christlichen Europa. Vierhundert Jahre nach ihrer Entstehung, im Jahr 1543, wurde sie auf Betreiben des Zürcher Humanisten und Theologen Theodor Bibliander (1504-1564) erstmals gedruckt. Bibliander zog für seine Editionsarbeit u.a. eine arabische Koranhandschrift zu Rate, die der Kardinal Johannes von Ragusa 1437 auf das Basler Konzil gebracht hatte und die noch heute im Besitz der Basler Universitätsbibliothek ist. ${ }^{49}$

1647 erschien in Paris die erste direkte Übersetzung des Korans in eine europäische Volkssprache. Der Übersetzer, der Diplomat und Orientalist André du Ryer (gest. 1688), der auch für die Rezeption des persischen Dichters Sa'dī in Europa eine Rolle spielt, zog für seine Übersetzung ins Französische auch arabische Korankommentare heran und ge-

48 Die älteste Handschrift befindet sich in Paris, Bibliothèque de l'Arsenal, MS lat. 1162; vgl. Thomas E. Burman, Religious Polemic and the Intellectual History of the Mozarabs, c. 1050-1200 (Brill's studies in intellectual history 52). Leiden, New York, Köln 1994, S. 84.

49 Basel, UB, A III 19. Näheres zu Bibliander und seinem Interesse für den Koran findet sich bei Hartmut Bobzin, Der Koran im Zeitalter der Reformation. Studien zur Frühgeschichte der Arabistik und Islamkunde in Europa (Beiruter Texte und Studien 42). Stuttgart 1995, S. 159-275. 
langte so zu einem authentischeren Verständnis des Textes als noch Robert von Ketton. Schon das Vorwort zur Übersetzung aber ließ erkennen, dass sich auch bei du Ryer die üblichen Vorurteile gegen den Koran wiederfanden. ${ }^{50}$ Dies änderte sich erst im Lauf der europäischen Aufklärung und ganz besonders durch die englische Koranübersetzung von George Sale (1697-1736), die 1734 erschien und bis ins 20. Jahrhundert hinein nachgedruckt wurde. Rezeptionsgeschichtlich bedeutsam sind auch Johann Wolfgang von Goethes Aussagen zum Koran, die er in seinen ,Noten und Abhandlungen zu besserem Verständnis des West-östlichen Divans' niederschrieb. Goethes Reaktion auf das Phänomen „Koran“ war Ausdruck eines gebildeten und an der Erschließung einer fremden, aber als faszinierend empfundenen Kultur interessierten Bürgertums des 18. und 19. Jahrhunderts. Erstaunlicherweise blieb jedoch die westliche Islamwissenschaft des 19. und der ersten Hälfte des 20. Jahrhunderts, zumal die deutschsprachige, in der Sicht auf den Koran hinter der Sensibilität Goethes zurück, wie Stefan WILD gezeigt hat. ${ }^{51}$ Da religiöse Vorurteile inzwischen kaum mehr thematisiert wurden, konzentrierte man sich besonders auf Sprache und Stil des Korans. Sie wurden einer oft harschen Kritik unterzogen. Bedingt war diese Negativwertung, wie WILD feststellt, durch drei Faktoren: ${ }^{52}$ (a) die Verkennung des liturgischen Rezitationscharakters des koranischen Textes; (b) die Verkennung der Eigenart koranischer Kurzverweise auf einen den Hörern bereits bekannten Erzählungsschatz; (c) den Mangel jeglichen rezeptionsgeschichtlichen Zugangs zur Bewertung der literarischen Qualität des Korantextes. Man verkannte insbesondere, dass ein ästhetisches Urteil über den Korantext als Kunstwerk nicht von der Verehrung getrennt werden kann, die er in einer islamisch bestimmten Umwelt genießt; denn jedes Kunsterlebnis, so auch das Erlebnis der koranischen Rezitation, ist ein Produkt sozialer Kooperation und ein Ausdruck geistiger Gemeinschaft - dieser rezeptionstheoretisch entscheidende Aspekt wurde in der damaligen Islamwissenschaft jedoch weitgehend ausgeblendet, die eigene negative ästhetische Wertung, die man als „objektiv“ verstand, wurde absolut gesetzt. Insofern konstituierte sich dadurch, wie WILD mit Recht anmerkt, ein Zug des orientalistischen Diskurses. ${ }^{53}$

Unter den deutschen Koranübersetzungen nach wie vor unerreicht in der Vermittlung des koranischen Sprachstils ist die Teilübersetzung von Friedrich RÜCKERT (1788-1866). ${ }^{54}$ Im wissenschaftlichen Kontext wird meist die Übersetzung Rudi PARETS zitiert, die zwar etwas trocken, aber um philologische Genauigkeit und größtmögliche Textnähe bemüht ist. ${ }^{55}$ Eine neue deutsche Übersetzung des Korans wurde 2010 von Hartmut und Katharina BobzIN vorgelegt. ${ }^{56}$ Praktisch ist die zweisprachige Koranausgabe von Adel Theodor KHOURY (2004) mit arabisch-deutschem Paralleltext. Für eine kritische Diskussion deut-

\footnotetext{
50 Bobzin (Anm. 49), S. 14.

51 Stefan Wild, „Die schauerliche Öde des heiligen Buches“. Westliche Wertungen des koranischen Stils. In: Alma Giese u. J. Christoph Bürgel (Hgg.), Gott ist schön und er liebt die Schönheit. Festschrift für Annemarie Schimmel zum 7. April 1992 dargebracht von Schülern, Freunden und Kollegen. Bern u. a. 1994, S. 429-447.

52 Ebd., S. 440.

53 Ebd., S. 445.

54 S. Anm. 4.

55 Der Koran. Übers. v. Rudi Paret. Stuttgart 1966.

56 S. Anm. 20
} 
scher seit Beginn des 20. Jahrhunderts erschienener Koranübersetzungen vergleiche man den Beitrag von Matthias Radscheit. ${ }^{57}$

3. Historische, sozialgeschichtliche und literarische Kontextualisierung des Korans; seine ästhetische Dimension

Der Koran ist in einem Umfeld entstanden, das noch wesentlich von der hellenistischen Kultur der Spätantike geprägt war. Die Sicht auf die „,noch-nicht-islamische“ spätantike Dimension, ${ }^{58}$ die der Koran auch hat, öffnet der Forschung neue Zugänge. So kann die besondere rhetorische Prägung des Korans auch als Signal für seine Zugehörigkeit zur reichen rhetorischen Tradition des Hellenismus verstanden werden. Weiter wäre die interessante Frage zu beantworten, inwieweit bereits der Koran Schauplatz spätantiken Wissenstransfers ist, ${ }^{59}$ jenes Vorgangs, der in abbasidischer Zeit institutionalisiert wurde und in der Übersetzung griechischer philosophischer, naturwissenschaftlicher und medizinischer Basistexte ins Arabische gipfelte - Texte, die, sobald sie der arabischsprachigen Koiné erschlossen waren, Gegenstand eigenständiger wissenschaftlicher Auseinandersetzung wurden. ${ }^{60}$ Von zentraler Bedeutung für die Kontextualisierung des Korans sind auch seine Bezüge zu den älteren monotheistischen Nachbarreligionen und deren Textzeugnissen, in erster Linie der Bibel. ${ }^{61}$ Ein systematischer Vergleich von Bibel und Koran als literarischen Texten sowie als Zeugnissen sich wandelnder theologischer Konzeptionen fehlt allerdings bis heute. ${ }^{62}$ Mit Blick auf die starke Präsenz des syro-aramäischen Christentums und dessen Liturgie im spätantiken Vorderen Orient wurden in Bezug auf eine mögliche Abhängigkeit des Korans auch spektakuläre - und spekulative - Thesen entwickelt, insbesondere von Christoph LuXENBERG, der den Koran als eine mit syrischen Elementen durchsetzte arabische Übersetzung eines ursprünglich syrischen - und damit christlichen - Urtextes auffasste. Mithilfe zahlreicher syrischer Etymologien versuchte LUXENBERG, diesen angeblichen Urtext zu rekonstruieren. Sein bekanntestes Beispiel sind die im Koran erwähnten Paradiesjungfrauen (hürun 'in), bei denen es sich nach der Bedeutung des angeblich zugrundeliegenden syrischen Wortes in Wirklichkeit um weiße Trauben handle. LuXENBERGs auf reduktionistischen Argumentationsmustern beruhende und tendenziös formulierte Thesen stießen auf heftige Kritik, auch und besonders seitens der Semitistik, und können heute als widerlegt gelten. ${ }^{63}$ Das soll nicht heißen, dass im Koran nicht auch syrische Traditionen rezipiert worden sind - schon die Nähe des syrischen qeryānā zu arabisch qur'ān deutet

57 Matthias Radscheit, Aktuelle deutsche Koranübersetzungen im Überblick. CIBEDO. Beiträge zum Gespräch zwischen Christen und Muslimen 13 (1999), S. 124-135.

58 So die Formulierung Neuwirths (Anm. 1), S. 67.

59 Dazu Neuwirth (Anm. 1), S. 727-729.

60 Zur griechisch-arabischen Übersetzungsbewegung und ihren weitreichenden kulturhistorischen Konsequenzen vgl. Dimitri Gutas, Die Wiedergeburt der Philosophie und die Übersetzungen ins Arabische. In: Ulrich Rudolph (Hg.), Philosophie in der islamischen Welt. Bd. 1: 8.-10. Jahrhundert (Grundriss der Geschichte der Philosophie. Begr. v. Friedrich Ueberweg). Basel 2012, S. 55-91.

$61 \mathrm{Zu}$ Aspekten der koranisch-biblischen Intertextualität vgl. jetzt die Untersuchung von Gabriel Said Reynolds, The Qur'ān and its Biblical Subtext. London, New York 2010.

62 Neuwirth (Anm. 1), S. 568; für zahlreiche Denkanstöße zum Thema Bibel und Koran vgl. ebd., S. 561 612.

63 Vgl. neben Wild (Anm. 30), S. 634-640 auch Neuwirth (Anm. 1), S. 98-102. 
darauf hin -, doch bedarf es hier einer differenzierten Herangehensweise, die u. a. nicht unausgesprochen die Vorstellung von einer Epigonalität des Korans zugrunde legt.

Aus sozialgeschichtlicher Perspektive ist die Fokussierung auf die frühislamische Gemeinde als aktives Moment bei der Entstehung und Entwicklung des Korans ein Thema der neueren Forschung. Ein hochinteressantes Forschungsfeld, was die literarische Kontextualisierung des Korans betrifft, ist ferner das Verhältnis des Korans zur altarabischen Dichtung. Deren zentrale, von der bisherigen Forschung weitgehend ignorierte Bedeutung für ein besseres Verständnis der arabischen Seite des Korans hat Thomas BAUER in einem wegweisenden Artikel aufgezeigt. ${ }^{64}$ Aus dem Vergleich des Korans mit der zeitgenössischen arabischen Poesie geht hervor, dass sich Ersterer ganz wesentlich als Antithese zu Letzterer versteht; diese antithetische Stellung lässt sich sowohl auf inhaltlicher als auch auf formaler Ebene nachweisen, im Gebrauch rhetorisch-stilistischer Mittel, im Wortschatz und in der Verwendung der Grammatik. Obwohl der Koran nicht mit Poesie verwechselt werden durfte und sich daher von ihr abgrenzte, musste er dennoch ein Publikum erreichen und überzeugen, das ästhetisch an den Maßstäben der Poesie orientiert war. Ein besonders interessanter Aspekt des Verhältnisses zwischen Koran und altarabischer Dichtung ist das, was BAUER ,"negative Intertextualität“ nennt. ${ }^{65}$ Sie besteht darin, dass gewisse für die Dichtung typische grammatische, rhetorische und ästhetische Phänomene im Koran bewusst vermieden werden. Die bewusste Vermeidung sprachlich-stilistischer Besonderheiten hat aber, so BAUER, einen ebenso bestimmenden, wenn nicht gar bestimmenderen Einfluss auf die Gestaltung eines Textes wie das Gegenteil, nämlich die Ähnlichkeit, die sich zwischen gewissen Besonderheiten feststellen lässt. Gerade durch diese negative Intertextualität eröffnet die altarabische Dichtung den Weg zu einem besseren Verständnis mancher Eigenschaften des koranischen Textes.

Das Verhältnis des Korans zur altarabischen Dichtung und überhaupt seine Verortung in seinem arabischen sozialen Umfeld werfen auch neue Fragen zur paganen arabischen Kultur und Religiosität in der Zeit vor dem Islam, der sog. Ğāhiliyya, auf. Lange ging die Forschung dabei von einer Dekadenz der paganen Religion aus, die gleichsam den Boden für ein neues monotheistisches Konzept bereitet habe. Dieser Auffassung widersprach in jüngerer Zeit Ludwig AMMANN, der für die arabische Gesellschaft unmittelbar vor dem Erscheinen des Islams ein Nebeneinander von rituell praktizierter Religion und kultferner, aber sich mit den Sinnfragen des Lebens auseinandersetzender Dichtung annimmt. ${ }^{66}$ Der altarabischen Dichtung kommt somit auch nach der These AMMANNs prägende Bedeutung für das arabische soziale Umfeld zu, in dem der Koran entstand.

Die ästhetische Dimension des Korans hat von allem Anfang an eine wichtige Rolle in seiner Rezeption gespielt - bereits zu Beginn der Verkündigung in der Wahrnehmung der koranischen Sprache als „Gegenmodell“ zur altarabischen Dichtung, später bei der Entwicklung des bereits erwähnten Dogmas seiner Unnachahmbarkeit ( $i$ ' $g \bar{a} z)$ als literarischer

64 Thomas Bauer, The Relevance of Early Arabic Poetry for Qur'anic Studies Including Observations on Kull and on Q 22:27, 26:225, and 52:31. In: Neuwirth, Sinai u. Marx (Anm. 8), S. 699-732.

65 Ebd., S. 706.

66 Ludwig Ammann, Die Geburt des Islam. Historische Innovation durch Offenbarung (Essener kulturwissenschaftliche Vorträge 12). Göttingen 2001. Die Thesen Ammanns, die manche Anregung für künftige Forschung bieten, diskutiert Neuwirth (Anm. 1), S. 333-337. 
Text. ${ }^{67}$ Als einzigartiges Phänomen in Zusammenhang mit dem ästhetischen Erleben des Korans festzuhalten, ist seine Multimedialität, insbesondere in den Ausprägungen des hörbaren und des sichtbaren Korans; durch sie vollzog und vollzieht sich die Übertragung des heiligen Offenbarungstextes in andere Vermittlungsformen, vor allem jene der Kunst. Der „hörbare“ Koran, d. h. seine Rezitation, ist allgegenwärtiges Merkmal einer islamisch definierten Öffentlichkeit. Die Arten des Vortrags reichen dabei von der verhältnismäßig einfachen Rezitation bis zur artistisch ausgestalteten Kantilene. ${ }^{68}$ Der „,sichtbare“ Koran manifestiert sich in unzähligen Kunstwerken oft höchsten Ranges. Neben Inschriften auf Bauwerken ist hier vor allem die Buchmalerei zu nennen. Möglicherweise unter dem Einfluss des islamischen Verbots der bildlichen Darstellung belebter Wesen ${ }^{69}$ haben sich im Lauf der Entwicklung der arabischen Schrift verschiedene äußerst differenzierte kalligraphische Traditionen herausgebildet, für die der Koran der erste Referenztext bildete.

\author{
Prof. Dr. Renate Würsch \\ Universität Zürich \\ Asien-Orient-Institut - Abteilung Islamwissenschaft \\ Wiesenstrasse 9 \\ $\mathrm{CH}-8008$ Zürich \\ renate.wuersch@unibas.ch
}

67 Umfassend behandelt das Thema Navid Kermani, Gott ist schön. Das ästhetische Erleben des Koran. 3. Aufl. München 2007.

68 Für ältere Referenzaufnahmen vgl. Neuwirth (Anm. 13), S. 111.

69 Das Bilderverbot gründet nicht im Koran, sondern in den Überlieferungen über den Propheten Mohammed (hadīt). Vom Verbot der Darstellung betroffen sind Menschen und Tiere, die Lebensodem $(r \bar{u} h)$ haben, nicht aber Bäume und Pflanzen im Allgemeinen. Zugrunde liegt die Vorstellung, dass der Mensch durch die Erschaffung solcher Bilder versucht, Gottes Schöpfung zu imitieren, ferner, dass ein Bild Objekt des Götzendienstes werden kann; vgl. Daan van Reenen, The Bilderverbot, a New Survey. Der Islam 67 (1990), S. $27-77$, der auch ältere Literatur zum Thema, insbesondere die Beiträge von Rudi Paret diskutiert. Neuere Studien sind: Silvia Naef, Bilder und Bilderverbot im Islam. Vom Koran bis zum Karikaturenstreit. München 2007 und Almir Ibrić, Islamisches Bilderverbot. Vom Mittel- bis ins Digitalzeitalter (Religionswissenschaft 12). Wien 2006. 